\title{
Grammar for the 21st century
}

'For the foreseeable future, anyone with a serious interest in English grammar will have to take into account the " information this book contains.'

- David Crystal

- An entirely corpus-based grammar of English.

- 6,000 authentic examples are used from the Longman Corpus Network.

- British English and American English grammar.. is compared.

- Reveals the differences between spoken and written English.

- Based on a groundbreaking six year research. project carried out by an internationally renowned author team.

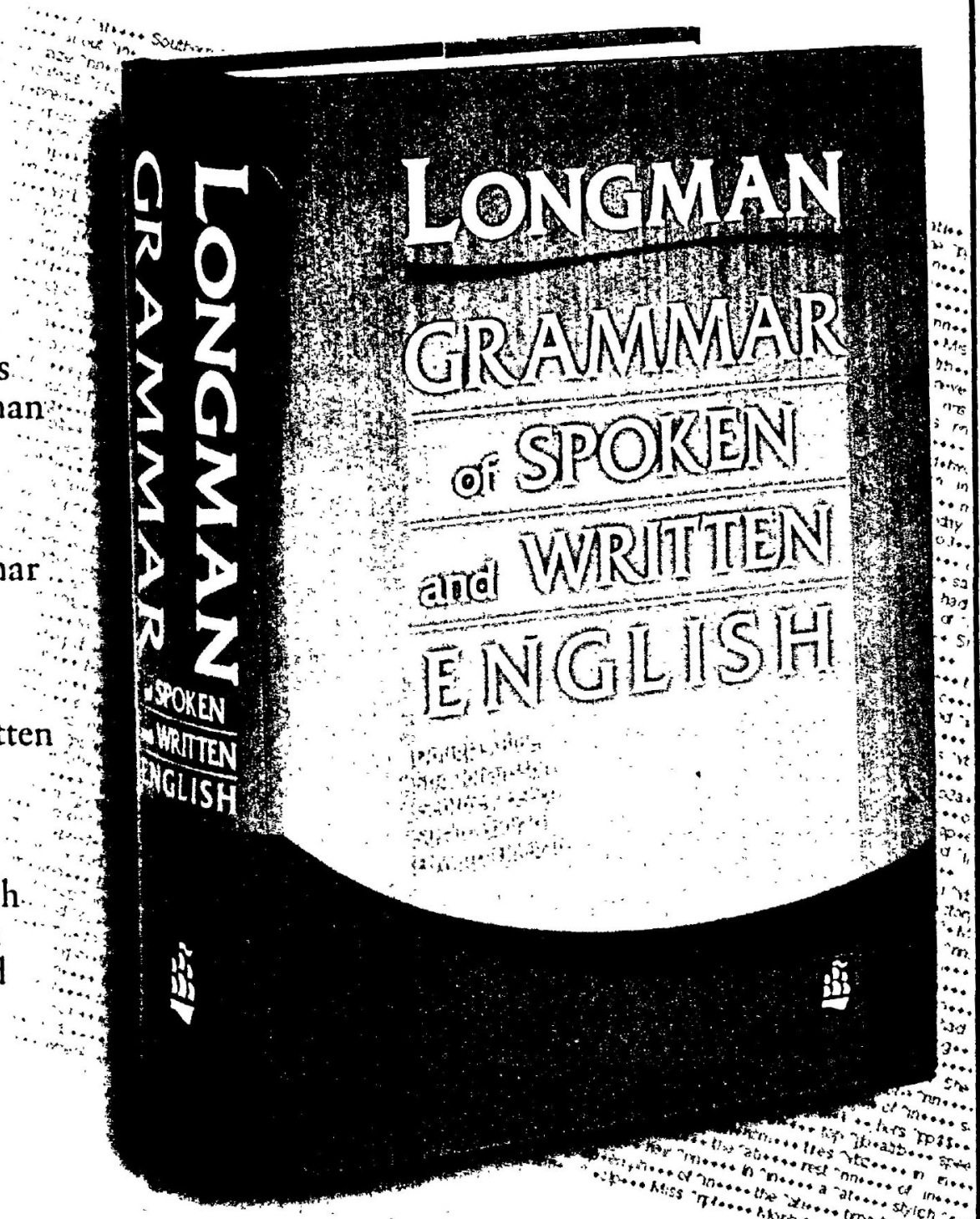

Longman Grammar of Spoken and Written English Douglas Biber, Stig Johansson, Geoffrey Leech, Susan Conrad and Edward Finegan Cased $\quad 0-582-23725-4 \quad 1216$ pages 1999

For more information, please contact Simon Collins Pearson Education, Edinburgh Gate, Harlow, Essex CM20 2JE, U.K.

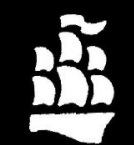
Tel: $+44(0) 1279623087$ Longman e-mail: simon.collins@pearsoned-ema.com ivww.longman-elt.com/dictionaries 


\section{language teaching}

April 2000 Volume 33 no 2

Contents

Using the journal

Page

State of the art James P. Lantolf on second language learning as a mediated process

Abstracts

239-309

Language teaching

97

310-338

Language learning

112

339-346

Reading

347-354

Writing

355-358

Language testing

359-361

Teacher education

362-363

Child language development

364-384

Bilingual education/bilingualism

385-392

Sociolinguistics

393

Pragmatics

New books and materials

List of abstractors

Subject index

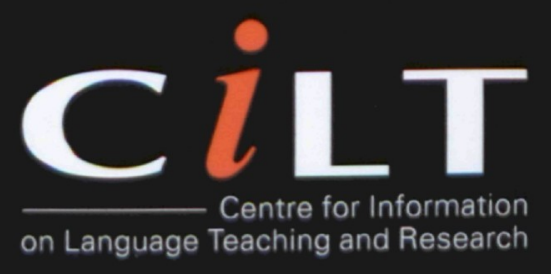

